\title{
Short follow-up of multisystem inflammatory syndrome after covid19 infection in children: case report
}

Angelo M. Acquafredda ( $\square$ angelo.acquafredda@aslfg.it )

ASL Foggia: ASL FG https://orcid.org/0000-0002-6231-027X

Chiara Lorusso

ASL FG

Anna L. S. Di Giovinazzo

ASL FG

Anna Maria Pastoressa

ASL FG

Maria Simone

ASL FG

Stefania Mastromattei

ASL FG

Maurizio Specchio

ASL FG

Pietro Cialdella

ASL FG

Pamela Vitullo

ASL FG

\section{Research Article}

Keywords: Covid19 infection, multisystem inflammatory syndrome (MIS), case report, lipid profile, followup

Posted Date: April 30th, 2021

DOl: https://doi.org/10.21203/rs.3.rs-379656/v1

License: (c) (i) This work is licensed under a Creative Commons Attribution 4.0 International License.

Read Full License 
Short follow-up of multisystem inflammatory syndrome after covid19 infection in children: case report

Angelo M. Acquafredda, Chiara Lorusso, Anna L. S. Di Giovinazzo, Anna Maria Pastoressa, Maria Simone, Stefania Mastromattei, Maurizio Specchio, Pietro Cialdella, Pamela Vitullo.

Pediatrics and Cystic Fibrosis Unit, Hospital "G. Tatarella "- Cerignola (ASL FG)

Correspondence: Angelo M. Acquafredda, MD Head of Pediatrics and Cystic Fibrosis Unit, Hospital “G. Tatarella "- Cerignola (ASL FG) E- mail address: angelo.acquafredda@aslfg.it 


\section{ABSTRACT}

Background: covid19 infection, in children compared to adults, often occurs in a pauci and/or asymptomatic manner, but in some cases, a multisystem inflammatory syndrome (MIS) may occur in the 4-6 weeks following the infection. There are few data on the features of MIS after the clinical recovery phase, therefore we have described three cases of children with post-covid19 infection syndrome. Case presentation: out of the three cases described, in two children the onset clinical symptoms were similar to Kawasaki syndrome, while in the other neurological impairment was prevalent. In none of the three there were gastrointestinal symptoms, while the signs of interstitial disease were constant on lung ultrasound. In all of them, there was an increase in the inflammatory markers, high levels of ferritin, lymphocytopenia and thrombocytopenia only in one case. The lipid profile at onset was characterized by an increase in triglyceride levels. In all cases the course was benign with resolution of the symptoms upon admission within 4-5 days. After 1 month from the clinical recovery phase, the patients showed normalization of cytokines, inflammatory markers and triglyceride levels, while the total cholesterol value increased. Covid19 infection leads to an acute phase response with increase of the triglyceride in addition to inflammatory markers and the signs of interstitial disease on lung ultrasound. Conclusions: the inflammatory markers and lung involvement normalize over 30 days, while an initial increase of the triglyceride - and later in total cholesterol - suggest a direct relationship between triglyceride and inflammatory markers at the beginning, and between total cholesterol and host immune response during the follow-up.

\section{KEYWORDS}

Covid19 infection, multisystem inflammatory syndrome (MIS), case report, lipid profile, follow-up 


\section{BACKGROUND}

The covid19 infection, in children compared to adults, often occurs in a pauci and/or asymptomatic manner and gets better easily but, in some cases, a multisystem inflammatory syndrome (MIS) may occur in the 4-6 weeks following the infection [1,2]. This syndrome, described in both the USA and Europe, can have different clinical features [3]; it is triggered by the release of cytokines and is due to an abnormal immune response to Covid19 infection [4]. Recent studies [5,6] have shown the clinical features and treatment of MIS following Covid19 infection, but there are few data on the characteristics of MIS after clinical recovery phase. We report three cases in children with MIS after covid19 infection to describe the onset symptoms, the course and the relative follow-up.

\section{CASE PRESENTATION}

\section{Patients}

Case 1: 14-month-old child without previous illnesses and with normal growth. He had been hospitalized for 5 days for hyperpyrexia without reporting other associated symptoms. Upon admission, the child showed skin pallor, pharyngeal hyperemia with fibrin deposition on the right tonsil, asthenia and difficult feeding. In the hours immediately after admission, the little one experienced extreme drowsiness associated with a slight neck rigidity and photophobia for which, in the suspicion of encephalitis, a computerized axial tomography of the brain and brainstem and a fundus oculi were performed and both of them were negative. No lumbar puncture for CSF examination was performed as the symptoms of meningism disappeared the next day and general health conditions improved.

Case 2: 3 years and 11 months old child who came to our observation for hyperpyrexia for 4 days, treated at home with macrolides and antipyretics, with negative history for previous illnesses and normal growth. Upon admission, a state of general neglect was noticed with the appearance of maculo-papular rash in the supraorbital region and cheeks, back, palm and soles of the feet and 
hands and pretibial region, laterocervical and retronucal lymphadenopathy, conjunctival hyperemia and cheilitis with pharyngeal hyperemia.

Case 3: 18-month-old child with hyperpyrexia for 5 days associated with cough. The growth was normal and no previous illnesses were reported. Upon admission, maculo-papular rash appeared on the trunk and soles of the feet, conjunctival hyperemia, cheilitis and sour breath diffused when listening to the chest.

\section{Outcome and follow-up}

In case 2 and 3 the onset clinical symptoms (Table1) were similar to Kawasaki syndrome while in the first case neurological impairment was prevalent and in none of them gastrointestinal symptoms were found. In all of them, there was an increase in inflammation markers including interleukin 6 (IL-6), high levels of ferritin, lymphocytopenia and thrombocytopenia only in one case (Table2). The lipid profile showed a significant increase in triglyceride levels (Table2) but with normal total, high density lipoprotein (HDL) and low density lipoprotein (LDL) cholesterol values. In all cases, the molecular nasopharyngeal swab was negative for covid19 infection but both IGM and IGG antibodies to covid19 (with higher IGG than IGM) were present in all children. None of them reported pulmonary lesions on chest X-ray, changes in cardiac conduction, morphology and/or dynamics or coronary lesions (negative electro and echocardiogram). On chest ultrasound signs of interstitial disease were found: in case 1 and 2 in the left parasternal site, in case 3 bilaterally. In all patients, we started intravenous therapy with ceftriaxone $(100 \mathrm{mg} / \mathrm{kg} / \mathrm{day})$ and methylprednisolone ( $1 \mathrm{mg} / \mathrm{kg} /$ day in two administrations) except in case 2 where the typical Kawasaki rash and the worst general clinical conditions also pushed to administer intravenous immunoglobulins for 2 days at a dose of $1 \mathrm{~g} / \mathrm{kg}$. In all cases, the course was benign with resolution of the symptoms detected upon admission within 4-5 days. The control of the hematochemical parameters after 1 month showed normalization of cytokines and inflammation markers in all of them, together with an increase in the IGG values in the serological test for covid of over $50 \%$. The triglyceride values 
normalized after the initial increase while the total cholesterol value increased (Table3). On pulmonary ultrasound, the signs of interstitial disease were no longer detectable.

\section{DISCUSSION AND CONCLUSIONS}

\section{Discussion}

The onset symptoms of MIS post covid19 infection were similar to those of Kawasaki syndrome in two children, while neurological involvement was prevalent in the other case. Two cases have recently been described in which covid19 infection subsequently induces a MIS Kawasaki-like associated with profuse diarrhea [7] - but the latter symptom was absent in our cases - while Whittaker et Al. [8] describe three categories of MIS with different clinical manifestations: a group with fever and signs of inflammation without the mucocutaneous signs of Kawasaki, one with left ventricular dysfunction and increased markers of myocardial involvement (Pro-BNP and troponin) and a third group similar, in all, to Kawasaki syndrome according to the AHA criteria [9]. Our cases, from a clinical point of view, are similar to those described by Taffarel et Al. [10] in which the children did not present any hepatic and cardiac impairment so as to require the aid of subintensive therapies, and the alterations highlighted by us on ultrasound thoracic symptoms were not related to lung disease and/or severe respiratory symptoms. In childhood, Lee and Al. [11] describe the clinical and laboratory features of MIS post-covid19 in which, in addition to the complete and/or incomplete clinical manifestations of Kawasaki syndrome, cytokine production patterns and simultaneous detection of cytopenia occur. In our three cases, a lymphocytopenia was always present and only in case 2 a thrombocytopenia was also highlighted, however it was short-lived. Covid infection induces an acute phase response which also leads to alterations in lipid metabolism [12]. The increase in triglycerides is caused by an increase in the secretion of VLDL as a result of lipolysis, by an increase in hepatic synthesis of free fatty acids and by the suppression of oxidation of fatty acids. The increase in total cholesterol found about 30 days after clinical recovery phase is less clear, because even if in adults with covid19 infection blood cholesterol 
levels are reduced and continue to decrease during hospitalization $[13,14]$, its increase could be attributed to the host immune response [15].

\section{Conclusions}

MIS after covid19 infection in children can manifest itself clinically in various ways but hyperpyrexia is a constant. MIS, in our cases, is not associated with gastrointestinal symptoms, it occurs in children under the age of 5 even with Kawasaki syndrome-like symptoms. Cardiac involvement, despite the positivity of myocardial distress markers, is never documented while, despite the scarcity of respiratory clinical signs, pulmonary ultrasound shows signs of interstitial disease. The inflammatory markers and lung involvement normalize over 30 days, while the lipid profile is characterized by an increase in triglycerides at admission followed by an increase in total cholesterol after the clinical recovery phase, suggesting at first, a relationship between triglycerides and inflammatory markers of MIS, while in the clinical recovery phase it seems that total cholesterol is related to the immune response elicited by the virus. A longer follow-up is required to clarify the relationship between the changes in the lipid profile, the inflammatory state and the immune response.

\section{LIST OF ABBREVIATIONS}

MIS: multisystem inflammatory syndrome;

KS: Kawasaki syndrome;

HDL: high density lipoprotein;

LDL: low density lipoprotein;

IGG: Immunoglobulin G;

IGM: immunoglubulin M;

CRP: C-reactive protein;

NT-proBNP: n-terminal pro-B-type natriuretic peptide;

IL-6: interleukin 6; 
R.B.C.: red blood cell;

W.B.C.: white blood cell;

$\mathrm{Hb}$ : haemoglobin;

T cholesterol: Total cholesterol.

\section{DECLARATIONS}

\section{Ethical approval and consent to participate}

Not applicable

\section{Consent for publication}

The patients' parents provided their consent to submission

\section{Availability of data and material}

Not applicable

\section{Competing interests}

The authors declare that they have no competing interests

\section{Funding}

None of the authors participating in the drafting of this case report has been sponsored

\section{Authors' contributions}

All authors participated in drafting the manuscript and managed the patients' follow-up.

All authors read and approved the final manuscript.

\section{Acknowledgements}

Not applicable 


\section{REFERENCES}

1. Consiglio CR, Cotugno N, Sardh F, Pou C, Amodio D, Rodriguez L et al. The immunology of multisystem inflammatory syndrome in children with COVID-19. Cel. 2020 Nov 12; 183 (4): 968-981

2. Rajapakse N, Dixit D. Human and novel coronavirus infections in children: a review. Paediatric Int Child Health, 2020 Jun 25; 1-20

3. Lami F, Scalabrini I, Lucaccioni L, lughetti L. The "perfect" storm: current evidence on pediatric inflammatory multisystem disease during SARS-CoV-2 pandemic. Acta Biomed 2020 sep 7; 91 (3); e 2020034

4. Esposto S, Principi N. Multisystem inflammatory syndrome in children related to sars-cov-2. Paediatr drugs 2021 Jan 22; 1-11

5. Feldstein L R, Rose E B, Horwitz S M, Collins J P, Newhams M M, Son M B Fetal. Multisystem inflammatory syndrome in U.S. children and adolescents. N engl J Med 2020 jul 23;383 (4): 334-336.

6. Abdel-Haq N, Asmar B I, DezaLeon M P, McGrath E J, Arora H S, Cashen K et al. SARS-Cov2- associated Multisystem inflammatory syndrome in children: clinical manifestations and the role of infliximab treatment. Eur J Pediatr 2021 Jan 16; 1-11

7. Licciardi F, Pruccoli G, Donina M, Parodi E, Taglietto M, Rosati S et al. SARS-Cov-2 induced Kawasaki-like Hyperinflammatory syndrome: a novel Covid phenotype in children. Pediatrics 2020. August; 146(2)

8. Wittaker E, Bamford A, Kenny J, Kaforou M, Jones C E, Shah P et al. Clinical characteristics of 58 children with a pediatric inflammatory multisystem syndrome temporally associated with SARS-Cov-2. JAMA 2020; 324(3):259-269.

9. McCrindle B W, Rowley A H, Newburger J, Burns J C, Bolger A F, Gewitz M, et al. Diagnosis, treatment, and long-term management of Kawasaki disease: A scientific statement for health professionals from the American Heart Association. Circulation. 2017 
10. Taffarel P, Baron F J, Rodriguez A P, Widmer J and Meregalli C. Multisystem inflammatory syndrome in children related to Covid-19: an uptade regarding the presentation of two critically ill patients. Arch Argent Pediatr 2021; 119 (1): 26-35

11. Lee P, Day-Lewis M, Henderson L A, Friedman K G, Lo J, Roberts J E et al. Distinct clinical and immunological features of Sars.Cov-2- induced multisystem inflammatory syndrome in children. J Clin Invest 2020 Nov 2; 130 (11)

12. Khovidhunkit W, Sun kim M, Memon R A,Shigenaga J K,Moser A H, Feingold K R et al. et al. Effects of infection and inflammation on lipid and lipoprotein metabolism: mechanism and consequences to the host. J lipid res 2004 jul 45(7): 1169-96

13. Kocar E, Rezen T, Rozman D. Cholesterol, lipoproteins, and COVID-19: basic concepts and clinical applications. Biochim biophys acta mol cell biol lipids. 2021 feb; 1866 (2): 158849

14. Feingold K R. Lipid and lipotrotein levels in patients with COVID-19 infections. In: endotext (internet), South Dartmounth (MA), MD Ttextcom, inc: 2000-2020 Nov 15

15. Cai F, Jin S, Chen G. The effect of lipid metabolism on CD4+ T cells. Mediators Inflamm.2021 Jan 5;2021:6634532.doi:10.1155/2021/6634532

TABLE 1. Clinical signs at admission in the three cases

\begin{tabular}{|l|l|l|l|}
\hline & Case 1 & Case 2 & Case 3 \\
\hline fever & YES & YES & YES \\
\hline lymphadenopathy & NO & YES & NO \\
\hline features KS like & NO & YES & NO \\
\hline Aspecific rash & NO & YES & YES \\
\hline $\begin{array}{l}\text { Upper respiratory tract } \\
\text { infection }\end{array}$ & NO & NO & YES \\
\hline $\begin{array}{l}\text { Gastrointestinal } \\
\text { synptoms }\end{array}$ & NO & NO & NO \\
\hline Neurologic synptoms & YES & & \\
\hline
\end{tabular}


TABLE 2. Lab tests upon admission in the three cases

\begin{tabular}{|c|c|c|c|}
\hline & Case 1 & Case 2 & Case 3 \\
\hline CRP mg/dl & 11,78 & 6,75 & 15,61 \\
\hline Procalcitonin $\mathrm{ng} / \mathrm{ml}$ & 0,4 & 0,8 & 54 \\
\hline NT-ProBNP pg/ml & 18416 & 6236 & 5286 \\
\hline Troponine ng/L & 0,8 & 40,9 & 6,4 \\
\hline D-Dimer mg/L & 1,55 & 1.69 & 7,88 \\
\hline IL-6ng/ml & 17,1 & 21,8 & 18,6 \\
\hline Ferritine $\mathrm{ng} / \mathrm{ml}$ & 143 & 701 & 509 \\
\hline R. B.C. $\times 10^{\wedge} 6 / \mu L$ & 4.830 & 4.200 & 4.590 \\
\hline W.B.C. $\times 10^{\wedge} 3 / \mu \mathrm{L}$ & 13.530 & 11.630 & 15.690 \\
\hline $\mathrm{Hb} \mathrm{g/dl}$ & 11,7 & 11 & 11,7 \\
\hline Platelets $\times 10^{\wedge} 3 / \mu \mathrm{L}$ & 162 & 92 & 211 \\
\hline T Cholesterol mg/dl & 142 & 109 & 138 \\
\hline HDL Cholesterol mg/dl & 17 & 18 & 8 \\
\hline LDL Cholesterol mg/dl & 65 & 68 & 50 \\
\hline Triglycerides mg/dl & 299 & 226 & 400 \\
\hline fibrinogen $\mathrm{mg} / \mathrm{dl}$ & 465 & 447 & 723 \\
\hline Lymphocytes \% & 12 & 21 & 20 \\
\hline
\end{tabular}

TABLE 3. Lipids profile after 1 month from clinical recovery phase

\begin{tabular}{|l|l|l|l|}
\hline & Case 1 & Case 2 & Case 3 \\
\hline Tot Cholesterol mg/dl & 265 & 236 & 199 \\
\hline HDL Cholesterol mg/dl & 48 & 103 & 143 \\
\hline LDL Cholesterol mg/dl & 189 & 99 & 37 \\
\hline Triglycerides mg/dl & 139 & 171 & 95 \\
\hline
\end{tabular}

